\title{
Aspetos da gramaticalização de ir como verbo auxiliar temporal
}

\author{
Telmo Móia \\ Universidade de Lisboa \\ Centro de Linguística da Universidade de Lisboa
}

\begin{abstract}
:
In this paper, various aspects concerning the grammaticalization of ir ('go') into a temporal auxiliary verb are considered, focusing on its current status as a posteriority operator in competition with various temporal suffixes of the tense system. Four issues will hold center stage: its coexistence with explicit posteriority tense suffixes, without a sense of redundancy emerging; its use in non-past and past scenarios in competition with the synthetic future and with the synthetic conditional, or imperfective past, respectively; its possible use in structures expressing an anteriority location relation (in association with future perspective points); its inflection in subjunctive, gerundive and infinitival forms, a rather poorly studied possibility. The overall conclusion will be that the grammaticalization process affecting $i r$ is still an ongoing process, which can be seen not only in the aspects studied apropos the abovementioned four issues, but also in a few other aspects - namely regarding the scarcity of its combination with some classes of predicates - that will be left for further research.
\end{abstract}

Keywords: grammaticalization, temporal auxiliary verbs, tense, temporal location, posteriority.

Palavras-chave: gramaticalização, verbos auxiliares temporais, tempo verbal, localização temporal, posterioridade.

\section{Introdução}

O português, como várias outras línguas do mundo, usa verbos de movimento (nomeadamente ir e vir) como verbos auxiliares temporais ${ }^{1}$, como resultado de um processo de gramaticalização. Neste trabalho, concentrar-me-ei no verbo ir e discutirei algumas das suas propriedades semânticas como auxiliar temporal, com destaque para a sua competição com outras formas regulares, sintéticas. Adotarei uma perspetiva reichenbachiana do tempo verbal, nos moldes da Discourse Representation Theory e recorrerei a corpora eletrónicos, principalmente de texto jornalístico, para aferir os usos predominantes no português contemporâneo (em

\footnotetext{
${ }^{1}$ Para alguns autores (cf. e.g. Gonçalves e Costa 2002), trata-se de verbos "semi-auxiliares", devido às propriedades sintáticas que os distinguem dos auxiliares típicos, como ter (auxiliar dos tempos compostos) ou ser (auxiliar da passiva). Por facilidade, manterei aqui a designação de "verbo auxiliar", num sentido lato, sem prejuízo de que a terminologia possa ser afinada, tendo em conta distinções gramaticais pertinentes do domínio da auxiliaridade.
} 
registos neutros e/ou formais) e ter uma visão mais clara do estádio atual do processo de gramaticalização. Sempre que for relevante, mencionarei diferenças entre o português europeu e o português brasileiro e entre o português e outras línguas, principalmente línguas românicas e o inglês.

Como referi, em português, o verbo de movimento ir transformou-se num verbo auxiliar temporal, geralmente descrito como um "marcador de futuro", que permite formar o chamado futuro perifrástico, ilustrado em (1a). Embora sejam reconhecidas diferenças de distribuição (e bem assim de registo) - nas quais não me irei aqui deter -, esta forma é apresentada como uma alternativa equivalente à expressão de valores futuros com o futuro simples (ou sintético ou imperfeito) e com o presente associado a valores de posterioridade, ilustrados em (1b) e (1c), respetivamente:

(1) a. Amanhã não $\{\underline{\text { vai }} / \underline{\text { irá }}\}$ chover.

b. Amanhã não choverá.

c. Amanhã não chove.

Diversos autores estudaram a evolução histórica do verbo de movimento ir e a sua gradual transformação num marcador de futuro, associando-a a um processo de gramaticalização. Lima (2001), em particular, discute vários momentos-chave, que não podem ser aqui considerados em pormenor, mas envolvem essencialmente, do séc. XVI em diante: um aumento na frequência de construções com sujeitos não humanos (e logo sem valor de finalidade) e sem implicação de movimento; novas possibilidades de uso de ir em combinação com formas verbais passivas ou com predicados inequivocamente estativos, por exemplo (além dos predicados de atividade - "verbos de ação", nos termos de Lima (2001) - predominantes em épocas precedentes). Processos semelhantes de gramaticalização de verbos de movimento ocorreram em muitas línguas do mundo, como se sabe da literatura - bastante extensa - sobre este tópico (cf. e.o. Hopper \& Traugott, 1993; Bybee et al., 1994; Dahl, 2000).

Como auxiliar, ir integra-se no sistema do tempo verbal da língua, a par das desinências temporais, e o seu papel tem de ser considerado essencialmente nesse sistema, em competição com as outras formas que o constituem. Na minha opinião, e apesar da extensa literatura sobre este operador já produzida, há algumas questões gramaticais que merecem um aprofundamento, 
pelo menos as quatro abaixo referidas, as três primeiras das quais serão exploradas adiante em secções autónomas deste trabalho, recorrendo a dados de corpora.

\section{A. possibilidade de flexionar o auxiliar temporal ir no futuro imperfeito}

(sem sensação de redundância)

A primeira questão respeita à possibilidade de flexionar o próprio auxiliar temporal ir no futuro, sem que daí advenha qualquer sensação de redundância. Assim, uma frase como (2a) abaixo, por exemplo, pode transmitir a mesma informação que uma frase como (2b) e crucialmente - não é sentida como pleonástica face a ela² .

(2) a. A sonda que foi agora enviada pela NASA irá aterrar em Marte.

b. A sonda que foi agora enviada pela NASA vai aterrar em Marte.

Como veremos com mais pormenor na secção 3, a flexão do auxiliar ir no futuro é muito comum, pelo menos em texto jornalístico. Eis alguns exemplos, retirados do corpus CETEMPúblico:

«A Assembleia da República não irá suspender os seus trabalhos durante a campanha para o referendo à regionalização.» (ext670319-nd-98b-2); «O jovem, que se encontra detido e que irá ser julgado no Tribunal de Guimarães, terá ateado as chamas para destruir diversas propriedades dos seus pais.» (ext617460-soc-93b-1); «Assim, por via democrática, iremos encontrar os mecanismos que nos façam sair da cauda dos países da União Europeia no que diz respeito aos indicadores civilizacionais (...).» (ext180141-opi-98b-2)

\footnotetext{
${ }^{2}$ Para alguns falantes, o uso do futuro (em vez do presente) no auxiliar parece favorecer uma interpretação de maior incerteza do enunciador relativamente à ocorrência das situações descritas. Embora esta subtil diferença modal não seja sentida de igual modo por todos, merecerá certamente maior atenção, em trabalhos posteriores. Em todo o caso, importa desde já notar que a hipótese simples de o futuro estar associado a maior incerteza prediria, incorretamente, a sua incompatibilidade com situações de ocorrência cientificamente previsível (cf. amanhã, $o$ pôr-do-sol irá ocorrer por volta das $18 \mathrm{~h} 05 \mathrm{~m}$ ) ou a maior estranheza da sua combinação com adjuntos do tipo de certamente ou sem dúvida (cf. «Os novos resultados também irão sem dúvida relançar o debate em torno da questão de saber onde é que teve origem a vida na Terra.», ext323840-nd-96b-2).
} 
$\mathrm{O}$ aspeto porventura mais interessante desta construção é que ela parece constituir um indício de que o auxiliar ir não está plenamente integrado no sistema temporal verbal do português como um equivalente perfeito das desinências de futuro, já que a dupla marcação de valor futuro - mediante o auxiliar ir e mediante os morfemas de futuro que lhe estão agregados - não apresenta, como já foi dito, qualquer sensação de redundância.

\section{B. uso do auxiliar temporal ir em cenários pretéritos}

A segunda questão respeita ao uso do auxiliar temporal ir em cenários pretéritos. Tratase de uma possibilidade reconhecida para as contrapartidas de ir em muitas outras línguas (por exemplo, o espanhol, o francês, ou o inglês ${ }^{3}$ ). Apesar de ser referida também em dicionários do português ${ }^{4}$, esta possibilidade é frequentemente ignorada em trabalhos sobre o futuro perifrástico português, tendo, no entanto, sido recentemente estudada, com algum pormenor, em Cunha (2015b). Exemplos relevantes desta construção estão em (4) e (5):

(4) Antes de seguir viagem, consultámos as previsões meteorológicas.

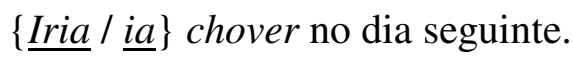

\footnotetext{
${ }^{3}$ Sobre o espanhol, Cartagena (1999: 2966) observa que "la construcción con ir presenta serias restricciones de selección en su valor temporal [i.e. como verbo auxiliar], ya que se da regularmente en presente y ante-copretérito (voy a hacer, iba a ir), pero no así en las otra formas (...)"; em particular, o autor refere que $i r$ não parece ocorrer nas formas de condicional ("Iría a hacer no fue documentada en nuestro corpus con valor temporal (...).", ibid.), o que contrasta nitidamente com o que acontece em português. Sobre o francês, Grevisse (1993: 1192) refere a possibilidade de usar aller, antes de infinitivo, como "auxiliaire de futur" no "indicatif présent" - e.g. il va mourir - e no "indicatif imparfait" - e.g. il glissait peu a peu, il allait tomber dans l'eau (além de, esporadicamente, em textos literários, no "subjonctif présent" - e.g. Ah! croyez-vous que j'aille dormir). Huddleston \& Pullum (2002: 212) dão exemplos com o predicado be going to no pretérito, referindo que ele está tipicamente associado a uma leitura modal (o que não é tão evidente em português, em que uma leitura estritamente temporal também é possível, como veremos melhor adiante) - "Preterite: be going doesn't entail that the complement situation was actualised (...). [In the sentence He was going to / would marry his tutor at the end of the year] we have a future in the past (...). (...) the would version entails that he did marry her. Was going does not have this entailment and quite often there will be an implicature of non-actualisation."

${ }^{4}$ Borba (1990), por exemplo, refere que ir pode ser um verbo auxiliar que "nas formas do presente, imperfeito, futuro e infinitivo + infinitivo indica futuridade" - Agora a gente vai se ver todo o dia (IN, 11); (...) os assassinos iam roubar laranjas (CS, 1); Pensei que fosse chover (SRD, 194); Mostrar-lhes o mundo que [nossas filhas] irão enfrentar (I, 65); Quando eu for buscar meu navio no Reino dos Corais, eu pago (SRD, 167); Em pouco tempo o comércio noturno iria falir (ESP, 2); Tenho vergonha de ir abrir a porta $(I, 23)$ [sublinhados meus].
} 
(5) Os resultados das eleições tinham sido surpreendentes.

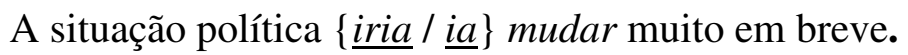

Neste caso, as formas perifrásticas - com ir no condicional ou no pretérito imperfeito estão em competição principalmente com o condicional simples: choveria, mudaria.

Dada a possibilidade de usar o auxiliar temporal ir em cenários pretéritos, temos de concluir que este verbo deve ser descrito como um marcador de posterioridade (ou prospetividade), mais do que como um marcador de futuro stricto sensu, como bem nota aliás Cunha (2015b).

\section{C. possibilidade (marginal) de usar o auxiliar temporal ir para expressar uma relação locativa de anterioridade}

A terceira questão envolve a possibilidade - tanto quanto sei ainda não estudada na literatura - de usar o auxiliar temporal ir para expressar uma relação locativa de anterioridade. Trata-se de uma possibilidade algo marginal, pelo menos em certas variedades da língua (nomeadamente no português europeu padrão), mas que está documentada em diversos corpora, como veremos mais adiante. Exemplos ilustrativos, para cenários não pretéritos e pretéritos, são dados em (6) e (7), respetivamente:

(6) O Pedro está a trabalhar afincadamente há várias horas.

?À meia-noite, já $\{\underline{\mathrm{vai}} / \underline{\mathrm{ira}}\}$ ter feito os trabalhos todos.

(7) O Pedro estava a trabalhar afincadamente há várias horas.

?À meia-noite, já $\{\underline{\text { iria }} / \underline{i a}\}$ ter feito os trabalhos todos.

Em (6), existe anterioridade a um ponto de perspetiva futuro, expressa pelo que poderíamos denominar de "futuro perfeito perifrástico". Como já foi dito, pelo menos para os falantes do português europeu padrão, não é um registo plenamente aceitável, sendo sentido como ligeiramente desviante face às formas com futuro perfeito comum (i.e. não perifrástico): 
(8) À meia-noite, já terá feito os trabalhos todos.

Em (7) (que é mais estranha que (6) para alguns falantes), existe anterioridade a um "ponto de perspetiva futuro do pretérito", expressa pelo que poderíamos denominar de “condicional composto perifrástico”. Neste caso, a estrutura compete com a versão canónica do condicional composto ilustrada abaixo (e tem preferencialmente uma leitura modal ou hipotética, usando os termos de Cunha, 2015b ${ }^{5}$ ).

(9) À meia-noite, já teria feito os trabalhos todos.

O facto de as possibilidades - ainda que marginais - de (6) e (7) não serem sentidas pelos falantes como totalmente impossíveis, e pelo menos (6) estar documentada em corpora, parece constituir um indício de que a gramaticalização de ir é um processo em curso, não totalmente estabilizado, e de que este operador ainda está a estender-se a diferentes nichos, não canonicamente ocupados, do sistema verbal.

\section{D. possibilidade de flexionar o auxiliar temporal ir no conjuntivo, no gerúndio e no infinitivo}

A quarta questão respeita à possibilidade de flexionar o auxiliar ir no conjuntivo (presente, pretérito imperfeito ou futuro imperfeito), no gerúndio e no infinitivo, ilustrada nalguns dicionários (pelo menos para o conjuntivo e o infinitivo ${ }^{6}$ ), mas - tanto quanto sei nunca realmente discutida do ponto de vista gramatical. O número de ocorrências em corpora é bastante elevado. Eis alguns excertos, do corpus CETEMPúblico, que parecem conter formas indubitavelmente do auxiliar temporal $i r$, o qual surge no conjuntivo, no gerúndio ou no infinitivo meramente devido ao contexto sintático em que está integrado.

\footnotetext{
${ }^{5}$ Uma "leitura prospetiva", ou real, em que se assume que a situação descrita ocorreu de facto (no passado), é preferencialmente codificada, nestes contextos, com o pretérito mais-que-perfeito composto: à meia-noite, já tinha feito os trabalhos todos. Note-se que o mais-que-perfeito expressa nesta sequência anterioridade a futuro do passado, e não simples anterioridade a passado, como regularmente acontece.

${ }^{6}$ Cf. nota 4 acima.
} 
(10)a. «A resposta talvez vá desapontar a Comissão, mas o trabalho irá prosseguir.» (ext158257-nd-92a-1); «Não há intelectual guineense que não vá chorar esta dor.» (ext17770-clt-98b-1); «Os dois projectos são semelhantes (...), embora a barragem de Vermiosa vá inundar mais do dobro de terreno (...) que a de Alfaiates (...).» (ext97090-soc-98a-1)

b. «Podia ter convocado Anita e Thomas (...), muito embora isso certamente fosse dar origem a fugas de informação.» (ext86430-nd-91b-2)

c. «(...) se um soldado for receber, como já foi anunciado, cerca de 400 contos por mês, "não se percebe onde possa estar o escândalo".» (ext297979-soc-96a-2)

(11) «Alguns dos deputados socialistas pensam que o partido (...) desaparecerá com o sistema eleitoral proposto por Hosokawa, indo por isso votar contra o pacote reformador (...).» (ext464962-pol-94a-1); «(...) a autarquia não teve até hoje qualquer resposta, indo accionar os mecanismos legais que permitam a clarificação da situação.» (ext437096-soc-92b-1)

(12) «Mas isto pode ser a alucinação do passageiro que entra neste avião (...) [,] olha pela janela e julga ir aterrar nas Bahamas.» (ext2456-eco-95a-1)

Trata-se naturalmente de contextos cuja consideração é necessária para uma visão mais completa do papel de ir no sistema temporal verbal do português e que colocam, além disso, interessantes questões semânticas, nomeadamente de avaliação da polivalência e possíveis ambiguidades do verbo ir, e bem assim da eventual ausência de alternativas sintéticas perfeitamente equivalentes. Por razões de tempo, deixarei uma análise mais pormenorizada desta quarta questão para investigação posterior. 


\section{Diversidade de relações locativas associadas ao auxiliar temporal $i r$}

Antes de passar à análise das questões que acabei de enunciar, deter-me-ei brevemente, nesta secção 2, na diversidade de relações locativas expressas pelas formas perifrásticas com $i r$, que é interessante - a meu ver - para a caracterização formal do valor de posterioridade comummente associado na literatura a este verbo auxiliar.

Um aspeto gramatical importante - que creio não ter sido suficientemente enfatizado é que o futuro perifrástico mimetiza o comportamento do futuro sintético (ou imperfeito) em todo o seu espectro de valores temporais, nomeadamente no que respeita à diversidade de relações locativas que pode codificar.

Se adotarmos uma visão reichenbachiana do tempo verbal, o futuro imperfeito tem dois valores básicos distintos (um deles subdivisível em dois). Um primeiro uso é dêitico, no sentido em que o momento da enunciação [n] é tomado como o ponto de perspetiva relativamente ao qual as situações descritas [ev] são consideradas. Numa estrutura de representação discursiva, do tipo usado na Discourse Representation Theory [DRT], este uso seria associado à condição $[\mathrm{ev}>\mathrm{n}]$ (equivalente a $[\mathrm{TPpt}:=\mathrm{n}] \wedge[\mathrm{ev}>\mathrm{TPpt}]$ ). Vejam-se os exemplos em (13):

(13) a. A sonda que foi agora enviada aterrará em Marte.

b. Estou certo de que o Pedro fará o que lhe pediste.

Nestes casos, a relação locativa é necessariamente de posterioridade (não podendo ser, por exemplo, de sobreposição). Todas estas sequências podem ocorrer nas formas perifrásticas com plena naturalidade: vai aterrar, vai fazer.

Um segundo uso é anafórico, na medida em que há um ponto de perspetiva futuro estabelecido no contexto discursivo, normalmente antes da forma verbal relevante, por meio de uma oração precedente ou de um adjunto temporal em posição inicial. A situação descrita é localizada relativamente a esse ponto de perspetiva previamente introduzido e não diretamente em relação ao momento da enunciação. Neste caso, há duas relações locativas acessíveis ao futuro imperfeito, sintético: posterioridade e - tipicamente, sempre que há predicações estativas envolvidas - sobreposição, como em (14) e (15), respetivamente. Numa estrutura de representação discursiva, estes dois valores seriam associado às condições [ev > TPpt] e [ev $O$ TPpt], respetivamente (em que [TPpt $>\mathrm{n}])$. 
(14) A Ana chega amanhã ao meio-dia. O Pedro levá-la-á a passear.

(15) A Ana chega amanhã ao meio-dia. O Pedro estará no aeroporto à espera dela.

Mais uma vez, estas sequências com pontos de perspetiva futuros podem ocorrer com as formas perifrásticas com plena naturalidade: vai levá-la, vai estar. Note-se que as estruturas com futuro perifrástico e relação locativa de sobreposição (a um ponto de perspetiva futuro previamente apresentado) são muito comuns em texto jornalístico. Veja-se:

(16) «O julgamento (...) está marcado para 6 de Julho, no Tribunal (...) da Sertã. Em manifestação silenciosa, $\underline{\text { vão }}$ estar no local mais de uma centena dos cerca de 600 bombeiros do concelho de Vila Franca.» (ext9299-soc-92b-2); «A partir de Maio, (...) talvez o seu uso venha a ser intensificado. (...) quem vier de Cascais para a Expo vai poder sair no Cais do Sodré e seguir daqui de metro até à gare do Oriente.» (ext1538421-soc-98a-2)

Esta possibilidade significa que não se pode descrever o futuro perifrástico como envolvendo sempre uma relação locativa de posterioridade, sem mais: o futuro perifrástico bem como o sintético, aliás - envolve antes ou uma relação locativa de posterioridade ou uma relação locativa de sobreposição. Porém, sintomaticamente, no caso da sobreposição tem de haver posterioridade no ponto de perspetiva. Por outras palavras, do ponto de vista formal, a posterioridade inerente ao futuro perifrástico pode estar ou na relação locativa apenas ([ev > n]), no ponto de perspetiva apenas ([TPpt $>\mathrm{n}]$ ) ou em ambos. Como veremos adiante, a análise do uso de ir em cenários pretéritos e em formas perfetivas confirma esta conclusão ${ }^{7}$.

Passemos agora às três primeiras questões referidas na secção 1 e à sua análise de acordo com os dados encontrados em corpora eletrónicos.

\footnotetext{
${ }^{7}$ Com as devidas adaptações no caso de cenários pretéritos, nomeadamente, substituição de $\mathbf{n}$ por um TPpt passado.
} 


\section{A construção irFUTURO IMPERFEITO + infinitivo}

Como já foi dito, o verbo auxiliar ir pode ser ele próprio flexionado no futuro imperfeito, o que se verifica, aliás, para qualquer dos valores de localização temporal já referidos: posterioridade a presente e sobreposição ou posterioridade a futuro. Eis exemplos do corpus CETEMPúblico com ponto de perspetiva presente (em contexto noticioso) - (17) - e com ponto de perspetiva futuro $-(18)$ :

(17) «Os tripulantes do Endeavour irão levar a cabo 419 manobras (...) de forma a poder apontar os sistemas de observação de bordo para diferentes ecossistemas (...).» (ext1561416-clt-soc-94a-1)

(18) «(...) os sociais-democratas viraram já as suas baterias para a festa da juventude, a realizar no domingo na Foz do Douro (...). Tudo indica que o presidente do partido irá estar presente (...).» (ext1561756-pol-91b-2); «Para já, as lontras são as únicas habitantes que podem ser vistas nos tanques do Oceanário, onde este mês deverão chegar cerca de 70 pinguins, que irão ocupar o habitat do Antártico, por enquanto ainda deserto de vida real.» (ext36082-clt-97b-2)

A possibilidade de flexionar o auxiliar ir no futuro é observada por muitos autores, mas as suas implicações não foram suficientemente enfatizadas, na minha opinião. O que esta possibilidade flexional indica é que um marcador redundante de posterioridade (as desinências de futuro do verbo auxiliar) pode ser introduzido nas sequências relevantes, formando, o que por mera facilidade de referência - poderia ser designado como futuro perifrástico "redundante". Porém, e crucialmente, os falantes não têm qualquer sensação de redundância com esta dupla marcação de valor. Por outras palavras, o papel dos dois elementos gramaticais - as desinências de futuro e o verbo auxiliar $i r$ - não parece ser sentido, ao contrário do que é costume assumir-se (de forma explícita ou implícita) na literatura, como totalmente equivalente, o que por sua vez sugere que o processo de gramaticalização ainda não gerou plena sinonímia, 
ou pelo menos uma sensação de plena sinonímia ${ }^{8}$.

No que respeita à frequência relativa da construção, uma pesquisa no corpus CETEMPúblico de sequências com ir no futuro simples imediatamente adjacente a um verbo no infinitivo gerou 25.385 ocorrências (cf. exemplos em (3) e (17)-(18) acima), uma indicação clara de que a perífrase redundante não é de modo algum uma estratégia rara. Por comparação, uma pesquisa paralela com ir flexionado no presente gerou mais de 193.916 resultados, numa proporção de 88,5 para $11,5 \%$.

A frequência bastante elevada de morfemas de futuro no verbo auxiliar parece separar o português de outras línguas onde verbos de movimento comparáveis a ir sofreram processos de gramaticalização semelhantes, como o espanhol, o francês e o inglês (nas suas variedades padrão, pelo menos ${ }^{9}$ ), em que a flexão futura do auxiliar não ocorre ou é pelo menos bastante rara.

Também é muito interessante notar que as formas perifrásticas com auxiliar ir no futuro e no presente coexistem em posições muito próximas no mesmo texto, inclusive em coordenação - cf. (19) -, o mesmo acontecendo, aliás, com as formas perifrásticas (com ir no futuro ou no presente) e com as formas sintéticas do futuro - cf. (20)-(22):

«O processo vai desenrolar-se por concurso e irá contemplar, primeiro, a TV Cabo Lisboa.» (ext1040-eco-95b-2); «O Governo Civil de Faro não irá comercializar esta primeira reedição (...), mas vãao fazê-lo duas instituições de solidariedade social farenses (...).» (ext172509-soc-93a-1)

\footnotetext{
${ }^{8}$ Em certos casos (relativamente pouco frequentes), os morfemas de futuro podem marcar valores próprios, como "concessão" (cf. "futuro concessivo", em Giomi, 2010: 120ss.); nestes casos, não há naturalmente plena equivalência entre as estruturas com presente e com futuro no auxiliar:

(i) A-A Ana vai mandar o currículo para essa empresa.

B - Irá mandar, mas duvido que seja escolhida.

${ }^{9}$ Segundo me disseram alguns colegas investigadores, existem variedades (americanas) do francês e do espanhol em que o uso de futuro no auxiliar (aller, ir) também é regular. Cartagena (1999: 2966, sublinhado meu) refere que "la construcción con ir (...) se da regularmente en presente y ante-copretérito (voy a hacer, iba a ir), pero no así en las otra formas (fue a hacer, iré a hacer, iría a hacer)"; este autor diz ainda que formas do tipo de iré a hacer são possíveis, mas expressam "en la mayoría de los casos contabilizados [en nuestro corpus] un marcado matiz de incertidumbre, que hereda seguramente de la forma simple, frente a hechos meramente futuros".
} 
(20) «(..) a missa será celebrada pelo bispo auxiliar de Lisboa, (...) e irá contar com a presença dos trabalhadores da TVI e seus familiares (...).» (ext809669-clt-92b1); «[Mário Soares] Irá pedir toda a documentação relativa à preparação da presidência comunitária, mas saberá proteger-se.» (ext555567-pol-91b-1)

(21) «De resto, ficou ontem a saber-se que no final da época o treinador Radomir Antic vai deixar o Atlético Madrid e rumará, em princípio, à Turquia.» (ext5236-des-98a-1)

(22) «A renovação do edifício da $\mathrm{BN}$ é que vai arrancar já em Outubro. Será adquirido mobiliário novo (...) e toda a área de referência irá sofrer obras de beneficiação (...).» (ext758111-clt-96b-1)

O que as combinações nestas sequências parecem indicar é que as várias formas de expressão de valores futuros tendem a ser usadas em português (pelo menos europeu) escrito como genuínas variantes, não associadas a distinções estilísticas acentuadas.

\section{O auxiliar temporal ir em cenários pretéritos}

Passemos agora à questão do uso do auxiliar temporal ir em cenários pretéritos, isto é, situações em que há um ponto de perspetiva passado, definido anaforicamente. Até bem recentemente, os estudos sobre este verbo auxiliar tendiam a ignorar as situações com este tipo de cenários. No entanto, como em muitas outras línguas (como o espanhol, o francês e o inglês), esta possibilidade é bem patente e perfeitamente regular, como mostra de forma pormenorizada Cunha (2015b).

Em termos de flexão do verbo ir, importa notar que há duas possibilidades aparentemente equivalentes e em variação livre, pelo menos em português europeu: o condicional (presente) e o pretérito imperfeito. Veja-se (23), que ilustra uma situação de posterioridade a um ponto de perspetiva passado (o momento em que o enunciador assistiu ao boletim meteorológico), associada à condição de DRT [ev > TPpt] (sendo [TPpt < n]).

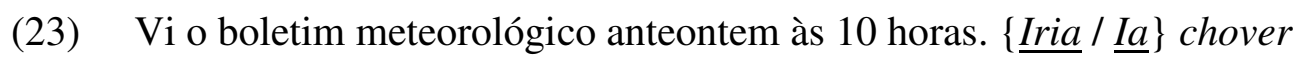
torrencialmente. 
Ambas as formas de flexão - condicional e pretérito imperfeito - são extremamente comuns em texto jornalístico e ocorrem em posições próximas, inclusive em coordenação (cf.(25))

(24) «(...) a Australian Broadcasting Corporation convidou-me para fazer uma «tournée» australiana com uma cantora que iria fazer a sua retirada da cena musical, e não queria cantar durante todo o concerto.» (ext474722-clt-91a-2); $\ll$ E era o mais jovem no duelo (trinta e poucos anos). Um deles $\underline{i a}$ largar $\mathrm{o}$ gatilho. (ext9849-soc-94b-2)

(25) «Recentemente, porém, o anúncio de que o posto da Urmeira iria fechar, porque o Governo Civil ia deixar de pagar aos médicos (...), deixou a população descontente (...).» (ext441864-soc-96a-3); «Muito calmo, Olívio terá dito aos amigos para não se preocuparem, que tudo se $\underline{i a}$ resolver e que mais tarde $\underline{i r i a}$ ter com eles.» (ext1335331-soc-96b-1)

Formas perifrásticas e sintéticas ocorrem também em posições próximas (à semelhança do que acontece em cenários não pretéritos):

(26) «Quando os jornalistas foram convocados, tudo parecia (...) estar já perfeitamente (...) programado. Braga de Macedo $\underline{\text { ia }}$ estar cerca de 45 minutos

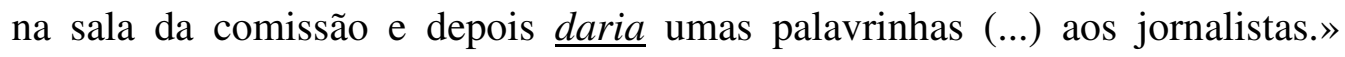
(ext1125013-eco92a-2)

Em termos de interpretação, um dos aspetos mais interessantes - para que Cunha (2015b) chama centralmente a atenção - é a possibilidade de $i r$ estar associados a duas leituras, neste tipo de contexto: uma "leitura prospetiva", em que predominam valores estritamente temporais de posterioridade ao passado e em que se assume que as situações descritas ocorreram de facto (o que naturalmente pode ser determinado a partir do momento - posterior - da enunciação), e uma "leitura hipotética", em que predominam valores modais e em que a ocorrência das situações descritas é deixada em aberto ou é negada (em valores que poderíamos designar de genuinamente hipotéticos e de contrafactuais, respetivamente). Alternativamente a 
valor temporal ou prospetivo e valor modal ou hipotético, poderíamos falar em valor real e valor virtual (das proposições associadas a ir), respetivamente. Como Cunha (2015b) nota, nalguns casos, o contexto linguístico é suficientemente informativo para se obter a leitura relevante - temporal/real ou modal/virtual, como em (27a) e (27b), respetivamente; noutros, o contexto não é suficientemente informativo, havendo vagueza relativamente à realização ou não da situação relevante, como em (27c) (e bem assim em (23) acima):

(27) a. «(...) a posição que (...) proclamaram não deixou de ter seguidores, entre eles frei Bartolomeu de las Casas, que $\underline{i a}$ fixar todos estes eventos, anos depois, na primeira “Historia de Las Índias”.» (CETEMPúblico, ext168349-soc-93b-2, apud Cunha, 2015b: 154) [FACTUAL]

b. «Dundee ia jogar hoje em Telavive (...), mas uma lesão sofrida no sábado fê-lo renunciar à viagem. (CETEMPúblico, ext24137-des-97a-4, apud Cunha, 2015b: 157) [CONTRAFACTUAL]

c. «Em Março passado, começaram os rumores de que a fábrica ia fechar mas ninguém acreditou.»(CETEMPúblico, ext39555-soc-93b-1, apud Cunha, 2015b: 166) [HIPOTÉTICO]

Qualquer dos valores é compatível quer com as formas de pretérito imperfeito, ilustradas acima (e as únicas estudadas em Cunha, 2015b), quer com as formas de condicional (que poderiam substituir o imperfeito nos exemplos acima com preservação plena da gramaticalidade), parecendo com efeito - como já foi dito - que as duas formas estão em variação livre.

O valor temporal/real (de posterioridade a um ponto de perspetiva passado), mas não curiosamente - o valor de modal/virtual, pode ainda ser veiculado pelo auxiliar temporal vir (a), no condicional ou no pretérito perfeito simples. Neste caso, assume-se a realização das situações descritas, depois do ponto de perspetiva passado e antes do momento de enunciação; a consideração deste último ponto parece ser aliás especialmente destacada pelo uso de vir (em vez de $i r$ ), parecendo haver uma preservação - de caráter metafórico - do sentido original dos dois verbos de movimento ("vir do ponto de perspetiva passado na direção do presente" vs. "ir do ponto de perspetiva passado para diante"): 
(28) A posição que proclamaram não deixou de ter seguidores, entre eles frei Bartolomeu de las Casas, que $\{\underline{\text { viria } / \underline{\text { veio }}}$ \} a fixar todos estes eventos, anos depois, na primeira "Historia de Las Índias".

Deixarei a análise do verbo auxiliar vir e das suas diferenças relativamente ao verbo $\mathrm{ir}$ para investigação posterior.

Importa agora notar que, interessantemente, em cenários pretéritos, pode ainda ser introduzido anaforicamente (por um adjunto inicial, por exemplo) um ponto de perspetiva posterior ao ponto de perspetiva passado, isto é, um ponto de perspetiva "futuro do pretérito", digamos assim. Em relação a este ponto de perspetiva - secundário, em certo sentido - pode ser estabelecida uma relação locativa de posterioridade ou de sobreposição, em perfeito paralelismo com o que acontece nos cenários não pretéritos. A condição numa estrutura de representação discursiva da DRT seria: [ev $\left.\bigcirc \mathrm{TPpt}_{2}\right]$ ou $\left[\mathrm{ev}>\mathrm{TPpt}_{2}\right]\left(\right.$ sendo $\left[\mathrm{TPpt}_{1}<\mathrm{n}\right] \wedge$ $\left.\left[\mathrm{TPpt}_{2}>\mathrm{TPpt}_{1}\right]\right)$. Vejam-se os exemplos abaixo, que ilustram a situação de sobreposição:

(29) Vi o boletim meteorológico anteontem às 10 horas. Duas horas mais tarde, à hora em que tínhamos combinado começar o nosso passeio, $\{\underline{\text { iria }} / \underline{\text { ia }}\}$ estar a chover torrencialmente.

(30) «Nas meias-finais, que se disputaram na manhã de ontem, EUA e Inglaterra não mais fizeram do que confirmar o seu favoritismo. (...) Logo a seguir, na parte da

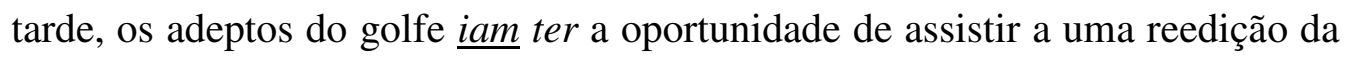
Ryder Cup (...).» (ext207027-des-93b-2); «Quando interrogado se no dia das presidenciais iria estar no Algarve ou em Moscovo, respondeu com uma gargalhada sonora (...).» (ext404990-clt-96a-1)

Em suma, verificamos, mais uma vez, que o valor de posterioridade associado a ir pode estar ou na relação locativa ou no ponto de perspetiva ou em ambos (generalização aplicável quer a cenários não pretéritos quer a cenários pretéritos).

Note-se ainda que, uma vez que as desinências de condicional podem, só por si, introduzir valores de posterioridade, as estruturas perifrásticas com condicional possuem sempre uma marcação dupla do valor de posterioridade - mediante o auxiliar ir e mediante as 
desinências que lhes são aplicadas, tal como acontece com ir flexionado no futuro, em cenários não pretéritos. Tal como nesses casos ainda, os falantes não sentem, sintomaticamente, qualquer efeito de redundância.

\section{A construção $i r+$ terinfINITIVo + particípio passado}

No que respeita ao tema deste trabalho - a gramaticalização de ir como auxiliar temporal -, é especialmente interessante notar que há usos (não padrão) do auxiliar ir em formas verbais que expressam anterioridade a um ponto de perspetiva estabelecido discursivamente (principalmente futuro, mas também, mais raramente, futuro do pretérito). Estas ocorrências por vezes sentidas como algo anómalas (pelo menos na variedade padrão do português europeu) - podem ser um sinal de mudanças gramaticais em curso. Comecemos pelos casos, mais comuns, de cenários não pretéritos.

Em português padrão, a anterioridade a um ponto de perspetiva futuro é expressa canonicamente mediante o futuro perfeito, sem contrapartidas com o auxiliar ir, como nos exemplos seguintes:

(31) a. À meia-noite, o Pedro já terá escrito as cartas.

b. Quando o pai chegar, o bebé já terá acordado.

Porém, como foi referido, há ocorrências - mesmo em corpora de texto jornalísticos de formas perfeitas (ou compostas) com o auxiliar ir, como as de (32a) e (32b) abaixo, paralelas a (31a) e (31b), respetivamente. Segundo apurei informalmente entre falantes brasileiros, estas formas são plenamente gramaticais em (pelo menos certas variedades do) PB.

(32) a. ?À meia-noite, o Pedro já vai ter escrito as cartas.

b. ?Quando o pai chegar, o bebé já vai ter acordado. 
Em termos de ocorrências em corpora, uma pesquisa no CETEMPúblico ${ }^{10}$ gerou apenas 3 resultados potencialmente relevantes, em que a ordem dos constituintes é crucial ${ }^{11}$, dois dos quais estão dados abaixo, em (33). Os falantes portugueses que consultei parecem considerar estas formas ligeiramente marginais, mas - sintomaticamente - não agramaticais:

«O Algarve, até final do próximo ano, vai ter resolvido o problema de abastecimento público de água.»(ext599534-soc-98b-4); «Os Hajakalma, que ganharam o concurso de rock de Cascais em 1993, vão ter editado, em princípio de Março, o seu registo de estreia (...).» (ext1057215-clt-94a-3)

Uma pesquisa equivalente no corpus seis vezes mais pequeno NILC-São Carlos gerou 6 resultados relevantes, entre os quais os quatro de (34), indicando que a construção está possivelmente mais expandida na variedade brasileira da língua. Alguns informantes brasileiros consultados confirmaram a plena aceitação das formas em questão nas suas variedades:

«Até o fim do mês de junho o Shopping Center Iguatemi vai ter inaugurado cinco novas lojas.» (par=Cotidiano--94b-1); «Quando eu assumir o governo, tudo de bom que poderia ser privatizado já vai ter sido vendido.» (par=Brasil--

\footnotetext{
${ }^{10}$ Pesquisa: "[V,v]oul[V,v]ais|[V,v]ail[V,v]amos|[V,v]ão" "ter" [temcagr="PCP"].

${ }^{11}$ Quando um SN ocorre entre ter e o particípio passado não existe, discutivelmente, formação de um tempo composto, mas antes uma estrutura participial de tipo "small clause"; nesta construção, o SN concorda em género e número com o particípio - vai ter [o problema resolvido]; vai ter [os problemas resolvidos]; vai ter [a situação resolvida] - e a colocação do particípio em posição pré-nominal dá origem a alguma marginalidade - ??vai ter [resolvidos os problemas], ??vai ter [resolvida a situação]. Inversamente, para haver futuro perfeito perifrástico, tem de haver adjacência entre ter e o particípio, ocorrendo o SN relevante em posição pós-participial; se não houver concordância entre particípio e SN, estamos claramente perante uma construção de futuro perfeito perifrástico vai ter resolvido os problemas, vai ter resolvido a situação; se ambos estiverem no masculino singular, a estrutura é potencialmente ambígua entre a construção marginal de "small clause" com SN pré-participial - ??vai ter [resolvido o problema] - e a construção, a meu ver menos marginal, com tempo composto perifrástico - ?[vai ter resolvido] o problema. Os dois excertos do CETEMPúblico transcritos em (33) ilustram ambos esta situação de SN masculino singular, pelo que a interpretação de tempo composto perifrástico é apenas a mais plausível de duas interpretações possíveis. Um terceiro excerto encontrado parece ter - apesar da ordem idêntica - uma interpretação preferencial como "small clause", o que mostra que a questão da ordem é porventura mais complexa e merecedora de atenção particular ( $\mathrm{O}$ plenário fundador da Associação Cívica Política XXI realiza-se no próximo dia 1 de Abril, ocasião em que surgirá uma nova forma de estruturar as organizações partidárias em Portugal. Como membro colectivo, esta associação vai ter inscrito um partido político: o partido Política XXI, ex-MDP.», ext925545-pol-95a-3). Nos corpora brasileiros, há exemplos com ausência de concordância entre SN e particípio (cf. primeiro excerto de (34)) e, portanto, com interpretação inequívoca de futuro perfeito perifrástico.
} 
94b-1); «Diz que (...) um dia "provavelmente vai 'tar bem velhinha e a ciência vai ter inventado um jeito de removê-las".» (par=Revista--94b-1); «A mudança de forma da molécula do vírus só acontece uma vez. Se ocorrer antes da hora da invasão, o vírus vai ter desperdiçado seu único tiro, e o sistema imunológico acaba matando-o.» (par=Mais--94a-1)

Genericamente, o facto de estas construções não serem consideradas totalmente agramaticais pelos falantes consultados - e ocorrerem em corpora-parece ser um indício claro de que ir como auxiliar temporal está a expandir o seu alcance a todas as formas envolvendo um valor de posterioridade, incluindo o nicho previamente não ocupado da anterioridade ao futuro.

Outro possível sintoma de que estamos perante mudanças em curso que ainda não se estabilizaram, ou estenderam por completo a todas as situações possíveis, é que não foram encontrados, nos dois corpora acima referidos (CETEMPúblico e NILC-São Carlos), quaisquer resultados envolvendo anterioridade em que o auxiliar ir estivesse - ele próprio - flexionado no futuro (em vez de no presente). Porém, em corpora significativamente mais extensos, nomeadamente no Corpus Brasileiro, que tem mais de 1000 milhões de palavras (em textos de registos muito diversos) foram encontradas duas instâncias desta construção:

«Até o final do ano, o brasileiro irá ter disputado competições em 16 países diferentes (...).»; «Caso saia derrotado do confronto (...), Kuerten irá ter acumulado sua $100^{\mathrm{a}}$ derrota quatro anos e quatro meses depois da sua estréia na elite do tênis (...).»

Pelo menos para os falantes de português europeu, esta construção (de futuro perfeito perifrástico "redundante", digamos assim) gera uma sensação de anomalia mais forte do que quando o auxiliar está no presente, o que pode indicar que a flexão de ir no futuro corresponde a um passo posterior no processo de gramaticalização (hipótese que naturalmente só pode ser comprovada através de análise em textos de diferentes épocas, que não é possível realizar no âmbito do presente trabalho).

Consideremos agora a expressão de relações locativas de anterioridade (a futuro) em cenários pretéritos. A possível extensão a cenários pretéritos das construções com relações 
locativas de anterioridade pode ser vista também como um sintoma de que a gramaticalização de ir como auxiliar temporal é um processo em curso. Canonicamente, para veicular os valores relevantes, usa-se em português, a forma composta do condicional, como em (36) (que parece ter preferencialmente uma leitura modal, ou hipotética):

(36) O Pedro começou a trabalhar bem cedo. À tarde, já teria acabado os dois relatórios.

Para expressar de forma inequívoca uma leitura estritamente temporal, ou prospetiva, é mais usual recorrer-se ao pretérito mais-que-perfeito composto (do indicativo) ${ }^{12}$, como em (37):

(37) O Pedro começou a trabalhar bem cedo. À tarde, já tinha acabado os dois relatórios.

Curiosamente - e, mais uma vez, de forma não totalmente canónica -, existe a possibilidade de marcar estes valores com o auxiliar ir, flexionado quer no condicional quer no pretérito imperfeito, em formas compostas, que poderíamos apelidar de "condicional perfeito perifrástico". Nestes casos, a leitura preferencial parece ser também a modal ou hipotética (tal como em (36) $)^{13}$ :

(38) O Pedro começou a trabalhar bem cedo.

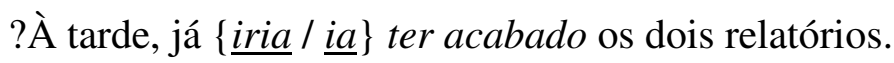

(39) Os Árabes entraram na Península Ibérica no ano 711.

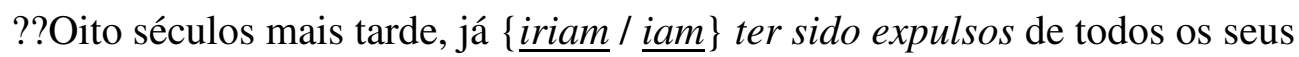
redutos. [maior estranheza, possivelmente porque a situação descrita é um facto histórico e não uma mera possibilidade]

\footnotetext{
${ }^{12}$ Note-se que, neste caso, o pretérito mais-que-perfeito expressa anterioridade a um ponto de perspetiva futuro do pretérito $\left(\left[\mathrm{ev}<\mathrm{TPpt}_{2}\right]\right.$, sendo $\left.\left[\mathrm{TPpt}_{1}<\mathrm{n}\right] \wedge\left[\mathrm{TPpt}_{2}>\mathrm{TPpt}_{1}\right]\right)$ e não a habitual anterioridade a um ponto de perspetiva passado $([\mathrm{ev}<\mathrm{TPpt}]$, sendo $[\mathrm{TPpt}<\mathrm{n}])$.

${ }^{13}$ Huddleston \& Pullum (2002 : 212, fn. 68), referem a existência de um "preterite perfect" de be going, que curiosamente - também tem uma leitura modal, e, segundo os autores, uma forte implicatura de interpretação contrafactual: "[an implicature of non-actualisation] is more pronounced in the preterite perfect [than in the preterite, he was going to marry his tutor]: He had been going to marry his tutor implicates, though of course does not entail, that he didn't do so."
} 
Mais uma vez - e de forma reveladora do caráter marginal que a construção ainda tem -, pesquisas nos dois corpora CETEMPúblico e NILC-São Carlos não produziram qualquer resultado, ainda que diversos falantes portugueses consultados não rejeitem fortemente a construção. No Corpus Brasileiro (de 1000 milhões de palavras) também não há nenhum exemplo indubitavelmente do tipo em causa. No entanto, neste corpus há dois exemplos envolvendo estruturas condicionais - que, discutivelmente, podem ser considerados de tipo comparável $^{14}$; neles, o auxiliar ir está flexionado no imperfeito ${ }^{15}$ e associado a orações condicionais, uma hipotética, no primeiro excerto, e outra contrafactual, no segundo excerto:

(40) «(...) eles sentiam que se a estrutura do poder evoluísse novamente (...) eles iam ter obstaculizado o seu processo de desenvolvimento.»; «Um preso que estava por perto (...) cumprimentou-me e disse (...): - Se fosse em outro lugar, você $\underline{i a}$ ter sofrido muito mais.»

\section{Outros indícios de gramaticalização em curso do auxiliar temporal ir - breves notas}

A observação de dados de corpora revela com especial clareza o estádio atual da competição entre formas sintéticas e perifrásticas de futuro, evidenciando que a gramaticalização do verbo de movimento ir como auxiliar temporal não é um processo totalmente acabado. Além das observações já feitas nas secções anteriores, que revelam diversos aspetos da incompletude desse processo, os corpora consultados - principalmente com texto jornalístico, como já foi referido - evidenciam pelo menos três outras situações que merecem destaque e que aqui apresentarei, sem no entanto nelas me deter aprofundadamente.

\section{A. Marginalidade ou raridade da combinação com verbos (principais) de movimento ir e vir}

J. Oliveira (2006), estudando principalmente o português brasileiro, salienta o caráter incompleto do processo de gramaticalização, destacando, por exemplo, a anomalia da combinação do auxiliar ir com o verbo principal (de movimento) ir na variedade padrão da

\footnotetext{
${ }^{14}$ A associação destas formas verbais a estruturas condicionais coloca problemas particulares cuja consideração excede o âmbito do presente trabalho e que deixarei para investigação posterior.

${ }^{15}$ Em consonância com o facto de que, em PB, o uso do condicional é fortemente condicionado em termos de formalidade do registo.
} 
língua, ainda que esta combinação surja - em PB - em certas outras variedades. Em português europeu, a combinação relevante também não produz resultados completamente naturais ${ }^{16}$ :

(41) a. O Pedro \{vai / irá $\}$ a Paris em Junho.

b. O Pedro $\{$ ?vai / *irá $\}$ ir a Paris em Junho.

A observação do corpus CETEMPúblico confirma a (quase) ausência dessa combinação (na variedade escrita do português europeu contemporâneo, no tipo de registo em apreço): apenas 1 resultado para a sequência $i r+i r^{17}$, em discurso direto, e num registo de sintaxe claramente não padrão:

(42) «O gajo não pode entrar onde é que não tem água, ele tem que estar lá onde é que tem a água. Se eu matar essa cobra a água que vai sair lá pode vir matar todas as pessoas que estão aqui. Isto tudo vai ir mesmo.» (ext1296002-clt-96a1)

Documenta ainda a grande raridade da combinação deste auxiliar com o verbo de movimento (principal) vir, ainda que o resultado não seja sentido normalmente como marginal: apenas 14 resultados para $i r+v i r$, em pesquisas paralelas ${ }^{18}$.

(43) «Sei de antigos empregados seus que $\underline{\text { vão }}$ vir de propósito a Lisboa para o funeral.» (ext304283-pol-94a-3); « ㅁ̃o vir alguns reforços, brasileiros, mas não

\footnotetext{
${ }^{16}$ A combinação parece melhorar substancialmente (com o auxiliar ir no presente, pelo menos), em combinação com expressões predicativas verbais com o verbo $i r$, de tipo idiomático ou afim (e.g. ir por água abaixo, ir ao fundo, ir contra a corrente - tudo $\{$ vai / *irá\} ir por água abaixo; se nada for feito, em breve Veneza $\{$ vai /*irá\} ir ao fundo. Não foram, no entanto, encontrados registos deste tipo no corpus CETEMPúblico.

17 Pesquisa: "[V,v]oul[V,v]ais|[V,v]ail[V,v]amos|[V,v]ãol[I,i]reil[I,i]rás|[I,i]rál[I,i]remos|[I,i]rão" "ir". Nas pesquisas sem os dois verbos adjacentes (com até duas palavras intervenientes), torna-se evidente que eles se podem combinar regularmente na mesma estrutura predicativa com outros verbos auxiliares de permeio: vai continuar a ir, vai acabar por ir, vai passar a ir, vai deixar de ir, etc.

${ }^{18}$ Por comparação, as formas de futuro sintético (virei, virás, virá, viremos, virão) apresentam mais de 3600 resultados, num proporção de mais de $99,5 \%$. O presente com valor futuro (vai, vem) parece ser a forma mais usada com estes dois predicados (ir e vir) para expressar valores de posterioridade.
} 
só.» (ext682658-des-98a-1); «ㅁou vir aqui até me cansar”, jura.» (ext1428410soc-98a-2)

Estas limitações relativas ao uso do auxiliar temporal ir com os verbos principais ir e vir contrastam claramente com a ausência de restrições comparáveis com outros predicados de movimento grosso modo equivalentes, como deslocar-se, regressar ou chegar, que ocorrem com plena naturalidade no futuro perifrástico, e bem assim com o que ocorre em outras línguas, como o francês ou o inglês, onde formas como va aller ou is \{going to / gonna\} go são perfeitamente regulares.

\section{B. Fortes restrições à combinação com verbos auxiliares modais}

Um segundo sintoma de que o processo de gramaticalização de ir não está concluído diz respeito à ausência de combinação deste auxiliar temporal com certos verbos modais, nomeadamente os epistémicos poder, dever e ser capaz (de) e o deôntico dever; esta impossibilidade contrasta com a regular combinação com outros verbos modais (não epistémicos), como os deônticos poder e ter de ou os marcadores de capacidade ou valor afim poder e ser capaz (de). Vejam-se os seguintes exemplos:

- valores epistémicos

(44) $\quad\{$ Deve / Deverá / * Vai dever $\}$ chover amanhã.

(45) $\quad$ PPode / Poderá / *Vai poder $\}$ chover amanhã.

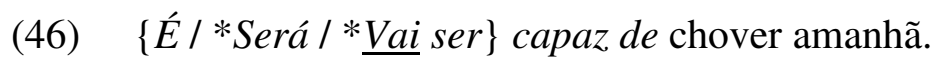

- valores deônticos

(47) Quando a lei for aprovada, a empresa $\{$ deverá $/ *$ vai dever $\}$ cumpri-la.

(48) Quando a lei for aprovada, a empresa \{terá / vai ter de $\}$ cumpri-la.

(49) Os pescadores \{poderão / $\underline{\text { vão }}$ poder $\}$ pescar mais em breve.

- valores de capacidade (cf. valor de conseguir)

(50) Em breve, \{poderei / vou poder $\}$ conversar contigo em alemão. Estou a aprender depressa. 
(51) Em breve, \{serei / vou ser $\}$ capaz de conversar contigo em alemão. Estou a aprender depressa.

Pesquisas no CETEMPúblico de $i r+$ dever adjacentes ${ }^{19}$ não produziram qualquer resultado e pesquisas de ir+poder e ir+ser capaz de adjacentes produziram 1681 e 53 resultados, respetivamente, mas sempre - em conformidade com o que foi dito acima - com valores não epistémicos:

(52) «O actual Presidente, bem como o vice-Presidente Ronald Diggs, não vão poder candidatar-se às eleições do próximo Outono.» (ext12958-pol-91a-3) [DEÔNTICO]; «Os cientistas $\underline{\text { vão }}$ poder escutar toneladas de gelo a quebrar-se por cima do submarino, quando este emergir para colher amostras da água e do gelo.» (ext47281-clt-soc-95a-1) [CAPACIDADE]

(53) «Ele e a sua equipa estão confiantes de que vão ser capazes de cumprir o prazo, embora admitam que é uma corrida contra o tempo.» (ext700443-soc-95b-1) [CAPACIDADE]

\section{Acentuadas variações na frequência de ocorrência com diferentes tipos de}

Aktionsart (em especial com valores de estatividade)

Como foi referido na secção inicial, Lima (2001) observa que foi essencialmente a partir do séc. XVI que começaram a observar-se combinações do auxiliar temporal ir com formas verbais passivas e com predicados inequivocamente estativos (em contraste com a combinação com predicados de atividade predominante em épocas precedentes). A observação de corpora contemporâneos mostra ainda uma correlação (apesar de imperfeita) entre a frequência das formas sintéticas vs. formas perifrásticas e o caráter estativo vs. caráter eventivo (ou não estativo) das situações descritas.

\footnotetext{
19 Pesquisas: "[V,v]oul[V,v]ais|[V,v]ail[V,v]amosl[V,v]ãol[I,i]reil[I,i]rás|[I,i]rál[I,i]remos|[I,i]rão" "dever"/"poder"/"ser" "capaz".
} 
Observando alguns núcleos lexicais prototípicos, escolhidos aleatoriamente, observaram-se os dados que estão no quadro seguinte (onde as células sombreadas correspondem às formas mais comuns $)^{20}$.

\begin{tabular}{|c|c|c|c|c|c|c|c|}
\hline \multirow{2}{*}{$\begin{array}{c}\text { predicados } \\
\text { estativos } \\
(3 \mathrm{sg} / \mathrm{pl})\end{array}$} & \multirow[t]{2}{*}{$\begin{array}{c}\text { futuro } \\
\text { sintético }\end{array}$} & \multicolumn{2}{|c|}{$\begin{array}{c}\text { futuro } \\
\text { perifrástico }\end{array}$} & \multirow{2}{*}{$\begin{array}{c}\text { predicados } \\
\text { eventivos } \\
(3 \mathrm{sg} / \mathrm{pl})\end{array}$} & \multirow[t]{2}{*}{$\begin{array}{c}\text { futuro } \\
\text { sintético }\end{array}$} & \multicolumn{2}{|c|}{$\begin{array}{c}\text { futuro } \\
\text { perifrástico }\end{array}$} \\
\hline & & $i r_{\text {PRES }}$ & $i r_{\mathrm{FUT}}$ & & & $i_{\text {PRES }}$ & $i r_{\text {FUT }}$ \\
\hline estar & $25017(84 \%)$ & 4596 & 252 & propor & $159(17 \%)$ & 691 & 95 \\
\hline permanecer & $1064(79 \%)$ & 236 & 51 & contratar & $14(23 \%)$ & 41 & 5 \\
\hline acreditar & $86(73 \%)$ & 31 & 1 & adquirir & $68(28 \%)$ & 144 & 28 \\
\hline manter & $1723(66 \%)$ & 729 & 166 & vender & $162(36 \%)$ & 258 & 34 \\
\hline continuar & $6085(61 \%)$ & 3655 & 240 & morrer & $232(44 \%)$ & 267 & 24 \\
\hline gostar & $103(56 \%)$ & 74 & 8 & & & & \\
\hline morar & $3(14 \%)$ & 15 & 4 & dançar & $38(54 \%)$ & 31 & 2 \\
\hline & & & & discursar & $79(69 \%)$ & 23 & 12 \\
\hline & & & & trazer & $1204(71 \%)$ & 419 & 64 \\
\hline
\end{tabular}

Quadro 1. Frequência (aproximada ${ }^{21}$ ) do futuro sintético e do futuro perifrástico com (uma seleção de) predicados prototipicamente estativos e eventivos

Assim, verbos prototipicamente estativos como estar, permanecer, acreditar, manter ou continuar dão prevalência das formas sintéticas acima de $60 \%$, enquanto que verbos prototipicamente eventivos como propor, contratar, adquirir ou vender dão prevalência das formas sintéticas abaixo de $40 \%$. Outros predicados, porém, dão prevalências distintas das

\footnotetext{
${ }^{20}$ Pesquisas: "[E,e]starál[E,e]starão", "[V,v]ail[V,v]ão" "estar" e "[I,i]rál[I,i]rão" "estar" (e afins, para os outros predicados).

${ }^{21}$ Registou-se apenas o número total de ocorrências de futuro sintético e futuro perifrástico, sem a preocupação de identificar eventuais casos em que as duas formas não estão em variação livre (e.g. casos de futuro sintético com valor modal, que não pode ser expresso com futuro perifrástico, ou casos de $i r+$ INFINITIVO, em que $i r$ não é um auxiliar ou, sendo um auxiliar, não compete com o futuro sintético ou com o futuro perifrástico com o auxiliar no futuro, como acontece e.g. na expressão de valores de iminência - cf. cuidado! a jarra vai cair! [*cuidado! a jarra \{cairá / irá cair\}!]); uma avaliação mais rigorosa das taxas de prevalência das diversas formas - sintética e perifrásticas - terá naturalmente de ter estas diferenças em conta. Também não se teve em conta - na pesquisa - a possibilidade de o auxiliar ir e o verbo principal não estarem adjacentes (e.g. vai lá/também estar, irá um dia vender, etc.), o que significa que o número de ocorrências do futuro perifrástico está subestimado, ainda que não num valor muito elevado (as primeiras 100 ocorrências relevantes de vai/vão estar com até duas palavras entre as formas verbais - "vailvãolVailVão" [] \{0,2\} "estar" - contém 4 ocorrências de não adjacência).
} 
esperadas - mais formas sintéticas ainda que o predicado seja eventivo (e.g. dançar, discursar, trazer) ou mais formas perifrásticas ainda que o predicado seja estativo (e.g. morar) mostrando que não estamos perante uma correlação perfeita. Naturalmente, a questão da correspondência entre formas de futuro e valores de Aktionsart (ou estatividade) carece de avaliação mais pormenorizada, não só tendo em conta as observações feitas na nota de rodapé 21, mas também tendo em conta os diferentes elementos que participam na composição aspetual, além do núcleo predicativo (cujo valor básico pode ser alterado, como sabemos, por diferentes itens da frase em que ocorre). Deixarei esta avaliação para investigação posterior, limitando-me aqui a registar o facto, interessante, de que o uso das duas formas de futuro em português parece ainda estar de algum modo dependente de valores aspetuais das expressões predicativas intervenientes.

\section{Conclusão}

Os dados analisados neste artigo - com especial destaque para os registos de corpora eletrónicos - mostram (i) que a gramaticalização de ir como auxiliar temporal é um processo ainda em curso, havendo forte competição com outras formas sintéticas grosso modo equivalentes e extensão a nichos ainda não canonicamente ocupados (nas variedades padrão da língua), (ii) que esse processo está possivelmente mais avançado na variante brasileira que na portuguesa, com a progressiva regularização de formas perfetivas perifrásticas, e (iii) que o traço de posterioridade - associado ou à relação locativa ou ao ponto de perspetiva, como vimos - conduz o processo e determina as ocorrências possíveis (não havendo, como se sabe, competição entre as formas sintéticas e as perifrásticas em sequências com valor exclusivamente modal, como a Ana terá agora uns vinte anos, suponho). Diversos aspetos do uso do auxiliar temporal $i r$ foram identificados, mas foram, pela sua complexidade, remetidos para investigação posterior; entre eles, destacam-se o uso do auxiliar ir flexionado no conjuntivo, gerúndio ou infinitivo - que tem recebido pouca atenção na literatura -, ou as sequências em que $i r$ + infinitivo não compete com o futuro sintético, ainda que ir possa nelas ser considerado também como um auxiliar temporal, como acontece na expressão de valores de iminência, em sequências como: cuidado! a jarra vai cair! ou sai da frente! o carro vai passar! 


\section{Referências}

Borba, Francisco da Silva (coord.) (1990) Dicionário Gramatical de Verbos do Português Contemporâneo do Brasil. São Paulo: Editora UNESP. 2. edição, 1991.

Bybee, Joan, Revere Perkins \& William Pagliuca (1994) The Evolution of Grammar: Tense, Aspect, and Modality in the Languages of the World. Chicago/London: The University of Chicago Press.

Cartagena, Nelson (1999) Los Tiempos Compuestos. In Ignacio Bosque \& Violeta Demonte (dir.), Gramática Descriptiva de la Lengua Española. Real Academia Española. Madrid: Espasa Calpe, pp. 2935-2975.

Cunha, Luís Filipe (2015a) Algumas Peculiaridades da Construção Ir + Infinitivo em Português Europeu". In Textos Selecionados. XXX Encontro Nacional da Associação Portuguesa de Linguística. Braga: APL, pp. 213-227.

Cunha, Luís Filipe (2015b) Algumas Considerações em Torno das Interpretações da Construção Ir + Infinitivo com Imperfeito. Diacrítica 29 (1), pp. 147-169.

Dahl, Östen (ed.) (2000) Tense and Aspect in the Languages of Europe. Berlin / New York: Mouton de Gruyter.

Fernandes, Francisco (1940) Dicionário de Verbos e Regimes. Porto Alegre: Editora Globo. 31. ${ }^{\text {a }}$ edição, 1979.

Giomi, Riccardo (2010) Para Uma Caracterização Semântica do Futuro Sintético Românico. Descrição e Análise dos Valores do Futuro do Indicativo em Português e Italiano. Dissertação de Mestrado, Faculdade de Letras da Universidade de Lisboa.

Gonçalves, Anabela \& Teresa da Costa (2002) (Auxiliar a) Compreender os verbos auxiliares. Descrição e implicações para o Ensino do Português como Língua Materna. Lisboa: Edições Colibri/Associação de Professores de Português.

Grevisse, Maurice (1993) Le Bon Usage. Grammaire Française. Paris/Louvain-la-Neuve: Éditions Duculot, 13. a edição revista.

Hopper, Paul G. \& Elizabeth C. Traugott (1993) Grammaticalization. Cambridge: Cambridge University Press. $2^{\text {nd }}$ edition, 2003.

Huddleston, Rodney \& Geoffrey K. Pullum (2002) The Cambridge Grammar of the English Language. Cambridge: Cambridge University Press. 
Kamp, Hans \& Uwe Reyle (1993) From discourse to logic. Introduction to modeltheoretic semantics of natural language, formal logic and Discourse Representation Theory. Dordrecht: Kluwer.

Lima, José Pinto de (2001) Sobre a Génese e a Evolução do Futuro com ir em Português. In A. S. da Silva (ed.), Linguagem e Cognição. A Perspectiva da Linguística Cognitiva. Braga: Associação Portuguesa de Linguística / Universidade Católica, pp. 119-145. [Reimpresso em Lima, José Pinto de (2014). Studies on Grammaticalization and Lexicalization. München: Lincom Europa, pp. 69-83.]

Móia, Telmo \& Evani Viotti (2004) Differences and Similarities between European and Brazilian Portuguese in the Use of the «Gerúndio». Journal of Portuguese Linguistics 3 (1), pp. 111-139.

Oliveira, Fátima (1985) O Futuro em Português: Alguns Aspectos Temporais e/ou Modais. In Actas do $1 .^{\circ}$ Encontro da Associação Portuguesa de Linguística. Lisboa: Associação Portuguesa de Linguística, pp. 353-373.

Oliveira, Fátima (2013) Tempo Verbal. In Eduardo Paiva Raposo et al. (orgs.), Gramática do Português. Lisboa: Fundação Calouste Gulbenkian, pp. 509-553.

Oliveira, Josane (2006) O Futuro da Língua Portuguesa Ontem e Hoje: Variação e Mudança. Tese de doutorado, Universidade Federal do Rio de Janeiro.

Oliveira, Josane \& Sílvia Olinda (2008) A Trajetória do Futuro Perifrástico na Língua Portuguesa: Séculos XVIII, XIX e XX. Revista da ABRALIN 7 (2), pp. 93-117.

Peres, João Andrade (1993) Towards an Integrated View of the Expression of Time in Portuguese (First Draft). Cadernos de Semântica 14. Faculdade de Letras da Universidade de Lisboa.

Corpora (disponíveis em http://www.linguateca.pt/ACDC/)

- CETEMPúblico 1.7 v. 7.6, c. 190 milhões de palavras, contendo apenas texto jornalístico (Público).

- Corpus Brasileiro, c. 990 milhões de palavras, contendo textos de diferentes tipos de registo.

- NILC/São Carlos v. 11.4, c. 32 milhões de palavras, contendo predominantemente (ainda que não exclusivamente) texto jornalístico (Jornal do Brasil, Folha de São Paulo). 